\title{
Canadian Association of Gastroenterology Practice Guidelines: Management of noncardiac chest pain
}

WG Paterson MD FRCPC

\section{OVERVIEW OF THE PROBLEM}

From $10 \%$ to $30 \%$ of patients who undergo cardiac catheterization for chest pain are found to have normal epicardial coronary arteries $(1,2)$. These patients are considered to have noncardiac chest pain (NCCP) and many are referred for evaluation of their upper gastrointestinal tract. By extrapolating American data, a conservative estimate for the Canadian incidence of NCCP is approximately 7000 new cases/year (3). Because many of these patient are referred to a gastroenterologist, it is imperative that the gastrointestinal consultant understand the nature of this condition and have a rational approach to its diagnosis and treatment. The objective of this document is to synthesize the available literature on the management of NCCP as it applies to practice of gastrointestinal specialists and to recommend practical guidelines for the management of this common problem.

\section{DIFFERENTIAL DIAGNOSIS}

A gastroenterology referral of a patient with NCCP is usually prompted by the belief that the pain might be esophageal in origin. However, it is important for the consultant to consider other diagnostic possibilities. It is first crucial to ensure that cardiac disease has been adequately excluded. Even in patients with normal coronary angiography the possibility of microvascular angina (4) should be considered. Pain from the chest wall, or disease of the pleura or mediastinum are usually obvious by history. Rarely, the pain of peptic ulcer disease is referred to the low retrosternal region. Biliary colic should also be considered in the differential diagnosis of

\section{SPONSORS AND VALIDATION}

This practice guideline was developed by Dr W Paterson MD FRCPC and was reviewed by

- Practice Affairs Committee (Chair Dr A Cockeram): Dr T Devlin, Dr J McHattie, Dr D Petrunia, Dr E Semlacher and Dr V Sharma

- Canadian Association of Gastroenterology (CAG) Endoscopy Committee (Chair - Dr A Barkun): Dr N Diamant, Dr N Marcon and Dr W Paterson

- CAG Governing Board

angina-like chest pain located in the low retrosternal region. Finally, an incarcerated hiatus hernia may be the cause of atypical low chest pain. In these patients the pain usually occurs postprandially.

\section{ATYPICAL ESOPHAGEAL PAIN: CAUSES AND PATHOGENESIS}

Sensory innervation of the esophageal body and lower esophageal sphincter is carried via the vagus nerves, the splanchnic and thoracic sympathetic nerves and the sympathetic cardiac branch from the stellate ganglion (5). Sympathetic afferents, which presumably carry much of the pain

GI Motility Education Centre, Queen's University, Kingston, Ontario

Correspondence and reprints: Dr WG Paterson, Division of Gastroenterology, Hotel Dieu Hospital, 166 Brock Street, Kingston, Ontario K7L5G2. Telephone 613-544-3400 ext 2332, fax 613-544-3114, e-mail paterson@post.queensu.ca 
sensation from the esophagus, travel via dorsal root ganglia into the spinal cord at T1 to L2. Cardiac pain fibres enter the spinal cord at the same levels; therefore, it is not surprising that esophageal pain can mimic cardiac pain both in distribution and quality.

There are several proposed mechanisms whereby esophageal disease or dysfunction can cause pain.

- Acid permeating the squamous epithelium can directly activate sensory nerve endings. This usually produces burning discomfort, but ambulatory $\mathrm{pH}$ and motility studies have clearly demonstrated that many patients experience angina-like pain coincident with acid reflux events (6-9). Although bile acids may be present in the refluxate, there is little evidence that these are a source of pain in reflux patients (10). Acid stimulation of the esophageal mucosa may also trigger myocardial ischemia via reflex mechanisms (11).

- 'Esophageal spasm' may cause pain, presumably by producing myoischemia. In general, manometric studies performed while patients spontaneously experience their NCCP have not demonstrated good correlation between the pain and spastic esophageal contractions. If the two were correlated, there would be a better association with the duration versus the amplitude of the contraction (12). Preliminary studies using ambulatory intraluminal sonography suggest that muscle contraction not detected by conventional intraluminal manometry may be the source of chest pain episodes in some of these patients (13).

- Esophageal distension can induce pain. However, most patients with obstructive esophageal disease develop gradual distension of their esophagus, which is rarely associated with discomfort. Acute obstruction with bolus impaction may cause pain through distension.

- Infiltrative diseases, the major one being malignant neoplasm, can cause atypical chest pain by directly invading sensory nerve fibres.

- There is mounting evidence that patients with atypical chest pain have abnormal sensory perception, as demonstrated by abnormal perception of esophageal balloon distension $(14,15)$. It is unclear whether this represents a problem with the sensory afferents or dysfunction at the level of the central nervous system.

\section{APPROACH TO DIAGNOSIS}

In a patient with a suspected esophageal cause of NCCP, a wide array of diagnostic tools is available to the clinician. Despite this, it often is difficult to establish clearly that the esophagus is the source of the pain.

Historical features: Davies and colleagues (16) examined historical features that help to differentiate atypical chest pain of esophageal origin from that of cardiac origin. A number of features suggested esophageal pain, including associated esophageal symptoms (such as heartburn, regurgita- tion and dysphagia, and relief with antacids), pain provoked by stooping and recumbency, marked variability in the degree of exercise that produced pain, onset of pain longer than 10 mins after exercise cessation, pain awakening patients from sleep, pain provoked by swallowing and pain that was severe in onset and then continued as a background ache for several hours. However, because there was considerable overlap between the two conditions, it was concluded that history alone was not particularly helpful in establishing a diagnosis. Other studies have come to similar conclusions $(17,18)$. If the pain is associated with other, more definitive esophageal symptoms such as heartburn, acid regurgitation and dysphagia, then the clinician is on much firmer ground in pursuing esophageal investigations. It is also important to explore psychosocial factors that may be contributing to the problem (19).

Physical examination: The physical examination is generally unhelpful in diagnosing the cause of atypical chest pain. It is nevertheless important to perform an examination to verify to the patient that the complaints are being taken seriously. Careful cardiac examination is important as is palpation of the chest wall to detect pain trigger points.

\section{INVESTIGATIONS}

A number of investigations are available to clinicians in their diagnostic work-up of patients with NCCP. Unfortunately, there is little scientific evidence supporting the utility of any of these tests in improving patient outcome.

Radiological studies - Chest $x$-ray: A chest $\mathrm{x}$-ray is useful to rule out significant disease of the mediastinum, pleura and lung parenchyma. This test is usually done in the course of excluding cardiac disease as a cause of chest pain. It rarely is of use in diagnosing esophageal disease, although it will detect a large incarcerated hiatus hernia or a significantly dilated esophagus.

Ultrasound: Abdominal ultrasound should be performed if the atypical chest pain has features suggestive of biliary colic, including unpredictable attacks of prolonged, steady pain in the low retrosternal area. Biliary colic rarely extends to the mid or upper chest. If biliary pain is suspected, liver function tests should also be done during or shortly after an attack of pain.

Upper gastrointestinal barium studies: Barium contrast studies of the esophagus have relatively low sensitivity and specificity in diagnosing gastroesophageal reflux disease (GERD) (20) and are usually of little diagnostic value when atypical chest pain is the sole presenting symptom. Contrast radiography is useful when the patient has associated dysphagia.

Upper gastrointestinal endoscopy: The value of endoscopy in NCCP patients is controversial. Even though up to $50 \%$ of all patients presenting with NCCP have GERD (21), no more than half of these patients will have endoscopic evidence of reflux esophagitis. Furthermore, in a recent study of 28 patients with NCCP, four were found to have reflux esophagitis yet 12 had pathological reflux on 24 h esophageal $\mathrm{pH}$ monitoring (17). All four patients with esophagitis had 
an abnormal ambulatory $\mathrm{pH}$ study. The low sensitivity of endoscopy in these patients has led some to argue that this test should not be done unless there are associated symptoms, such as dysphagia, that more specifically point to diseases of the upper gastrointestinal tract. However, endoscopy has the advantage of detecting other diseases of the proximal gastrointestinal tract, as well as Barrett's esophagus. Furthermore, erosive esophagitis provides an unequivocal rationale for aggressive antireflux therapy.

Esophageal manometry with provocative testing: For years esophageal manometry with provocative testing has been a major diagnostic tool in the evaluation of patients with NCCP, primarily because of the commonly held belief that 'esophageal spasm' underlies the pain in many of these patients. In recent years, however, the value of this diagnostic test in NCCP has been seriously questioned (22). We (23) found abnormal baseline manometry in approximately $60 \%$ of patients with NCCP, but most of these were relatively minor, nonspecific esophageal motor disorders of questionable clinical significance. In patients with NCCP but no dysphagia, it is distinctly rare to diagnose achalasia, the only esophageal motor disorder for which proven effective therapy is available, with manometry (24). There is also evidence that in patients diagnosed with nutcracker esophagus (hypertensive peristalsis), the most common manometric abnormality in NCCP patients $(23,24)$, the correlation between spontaneous episodes of chest pain and the hypertensive contractions is poor. It, therefore, can be concluded that in the absence of dysphagia, baseline esophageal manometry is of little, if any, value in the evaluation of NCCP patients.

Because it is rare that a patient experiences a spontaneous episode of chest pain during baseline esophageal manometry, most motility laboratories perform provocative testing during manometry in an attempt to precipitate the patient's pain. Three provocative tests are commonly used: esophageal acid perfusion (Bernstein test), cholinergic stimulation with either bethanechol or edrophonium, and esophageal balloon distension.

Acid perfusion reportedly reproduces the atypical chest pain seen in $10 \%$ to $50 \%$ of patients $(23-25)$. The highest yield comes from laboratories that use a perfusion port in the more proximal esophagus, thus exposing a greater length of esophagus to acid $(23,24)$. The Bernstein test was initially evaluated in patients with more typical reflux symptoms and was found to have reasonable sensitivity and specificity (26). However, it appears that this test may not be specific in patients with NCCP. Recent studies have reported that only a minority of patients in whom atypical chest pain was reproduced by acid perfusion had their spontaneous pain preceded by acid reflux during ambulatory esophageal $\mathrm{pH}$ monitoring $(6,8)$.

Provocative testing using either bethanechol or edrophonium has also been reported to reproduce chest pain in a significant proportion of patients $(8,23,24,27)$. This result may not be associated with the induction of spastic esophageal contractions. Unfortunately, this test also appears to lack specificity. A positive result does not necessarily mean that the patient's spontaneous chest pain episodes are due to esophageal spasm $(6,8)$, nor is there evidence that it predicts a response to therapy.

Esophageal balloon distension reportedly has a higher diagnostic yield than other forms of provocative testing $(28,29)$. Up to $60 \%$ of patients with NCCP have their pain reproduced during balloon distension. Again, this test's specificity is uncertain, and it remains to be demonstrated that a positive test is useful in guiding therapy. However this provocative test has been useful in helping us understand the pathophysiology of NCCP, in that it demonstrates visceral hyperalgesia in a significant number of patients. This is defined as a lowered sensory and pain threshold to esophageal balloon distension. Patients with such hypersensitivity often also have exaggerated sensitivity to esophageal acid perfusion. Theoretically, the demonstration of a hypersensitive esophagus by using balloon distension may guide therapy towards agents that affect visceral sensation.

Although esophageal manometry with provocative testing can suggest an esophageal cause of the pain, there is little evidence that the test is useful in guiding therapy. There is some evidence, however, that patients who have undergone this testing to establish an esophageal cause of their pain may subsequently cope better with the problem and use fewer health care resources $(30,31)$. This may be due to a lowering of patient anxiety following a positive esophageal diagnosis. Patients without a positive diagnosis may continue to worry about undiagnosed heart disease.

Twenty-four hour ambulatory $\mathrm{pH}$ monitoring: $\mathrm{A}$ number of studies have reported on the value of $24 \mathrm{~h} \mathrm{pH}$ monitoring in NCCP (32-35). The diagnostic yield of this test has varied widely from study to study, most likely because of different inclusion criteria. Overall, about $40 \%$ of patients with NCCP have either an abnormal degree of acid reflux on $24 \mathrm{~h} \mathrm{pH}$ monitoring, or a correlation between symptoms and reflux events (21). However, a pathological degree of gastroesophageal reflux on $\mathrm{pH}$ monitoring does not necessarily mean that the patient's atypical chest pain is reflux-related. Furthermore, a normal $24 \mathrm{~h} \mathrm{pH}$ study does not exclude reflux as a cause. Several studies have documented a correlation between individual acid reflux events and chest pain episodes in patients without pathological reflux $(7,8)$. The test appears to be more useful for its ability to temporally correlate episodes of chest pain with acid reflux. This approach is not without problems, however. By convention the $\mathrm{pH}$ electrode is placed $5 \mathrm{~cm}$ above the lower esophageal sphincter and, therefore, may fail to record reflux episodes that cause pain. An additional problem is that establishing a relationship between reflux events and chest pain is largely arbitrary. For instance, many studies have used a 'window' before and after a chest pain event, and score a reflux event occurring in this time interval as being positively correlated with the chest pain. By using such criteria, a reflux event occurring after the patient experienced pain is reported as responsible for the pain. This approach clearly inflates the true relationship between pain episodes and reflux.

Another major problem is that many patients with NCCP 
do not have pain on a daily basis. In this situation, ambulatory $24 \mathrm{~h} \mathrm{pH}$ monitoring is of limited utility because the patient may not experience a spontaneous pain episode during the recording. It is, therefore, recommended that $24 \mathrm{~h} \mathrm{pH}$ monitoring be used only in patients with frequent (ie, daily) episodes of pain. Because of the cost of this test and the limitations outlined above, many experts suggest that $24 \mathrm{~h} \mathrm{pH}$ monitoring be reserved for those who have failed empirical therapy with a proton pump inhibitor (PPI) (see below). In such patients, $24 \mathrm{~h} \mathrm{pH}$ monitoring with the patient on treatment will determine that the pain is either related to reflux that has been inadequately controlled by the PPI or unrelated to reflux.

Combined ambulatory esophageal $\mathrm{pH}$ and manometry recording: A number of centres have evaluated combined ambulatory $\mathrm{pH}$ and motility systems in patients with NCCP (6-9). In general, the added diagnostic yield with this test has been disappointing; at most $15 \%$ to $20 \%$ of pain episodes can be correlated with esophageal dysmotility. Furthermore, demonstrating that individual pain episodes correlate with dysmotility is of dubious clinical significance given the lack of effective therapy for the dysmotility.

\section{EMPIRICAL THERAPY AS A DIAGNOSTIC TEST}

In the past, therapeutic trials of antireflux treatment or smooth muscle relaxants were of questionable value because of relatively poor response to these agents, even when the suspected disorder (ie, reflux or esophageal spasm) was known to be present. The value of empirical therapy has changed with the advent of PPIs. Well over $90 \%$ of patients with acid reflux-related symptoms respond dramatically to PPI therapy (36); therefore, a short trial is now commonly used as a diagnostic test in NCCP. Failure to respond virtually excludes reflux as a cause. On the other hand, a dramatic resolution of the chest pain makes it likely that the pain was reflux-related. Recent studies have attempted to evaluate this approach and have documented a strong correlation between abnormal $24 \mathrm{~h} \mathrm{pH}$ monitoring and a symptomatic response to a PPI (37). Many would argue that a trial of PPI therapy is a cost effective approach in patients with NCCP, particularly because GERD is the one cause of NCCP that readily responds to treatment. A problem with this approach is that some patients have a placebo response, which may lead to unnecessary and costly long term therapy.

\section{TREATMENT}

There are three major approaches to the treatment of patients with NCCP:

- antireflux therapy;

- smooth muscle relaxants;

- drugs that affect visceral perception.

Ideally, treatment should be individualized to the pathophysiology of a given patient, but unfortunately this is often not possible.
Antireflux therapy: Theoretically, if NCCP is due to acid reflux, it should resolve following vigorous antireflux therapy. Surprisingly, there are few well controlled studies of antireflux treatment in NCCP patients. A number of open label studies using different forms of acid suppression or antireflux surgery $(33,38-41)$ have reported marked improvement in patients with NCCP. In most of these studies, the incidence of pathological reflux was much higher than in most series of NCCP patients.

In a recent study, Achem et al (41) randomly assigned 36 patients with NCCP and abnormal $24 \mathrm{~h}$ esophageal $\mathrm{pH}$ monitoring to either placebo or omeprazole ( $20 \mathrm{mg}$ bid) for eight weeks. Not surprisingly, these selected reflux patients with atypical chest pain markedly improved on omeprazole therapy versus placebo. Another study, published in abstract form (37), randomly assigned 21 patients with daily episodes of NCCP to either omeprazole $40 \mathrm{mg}$ in the morning and 20 $\mathrm{mg}$ in the evening, or placebo for seven days. This was followed by a two-week washout period and then crossover to the other treatment. All patients had endoscopy and $24 \mathrm{~h}$ $\mathrm{pH}$ monitoring before entry into the study. Eleven of $21 \mathrm{pa}-$ tients $(52.4 \%)$ had pathological reflux as diagnosed by $24 \mathrm{~h}$ $\mathrm{pH}$ monitoring (seven of these had erosive esophagitis). All 11 patients on omeprazole improved during therapy; eight of the 11 had at least a 50\% decrease in their symptoms. On the other hand, only seven patients improved on placebo, but in no placebo-treated patient was the improvement greater that $50 \%$. Only one patient with NCCP and no pathological reflux improved on omeprazole.

This study suggests that empirical treatment with high dose omeprazole may be useful in determining whether the pain is reflux-related. However, this population of NCCP patients had a relatively high frequency of abnormal reflux. This approach may not be as useful in a more typical patient population in which the incidence of pathological reflux ranges from $10 \%$ to $20 \%$.

Smooth muscle relaxants: Agents that decrease the force of esophageal smooth muscle contraction (eg, antimuscarinics, nitrates and calcium channel blockers) have been used extensively in the treatment of NCCP, particularly in patients with a hypercontractile esophagus. Unfortunately, the use of these agents is largely supported by only anecdotal reports. Two randomized, placebo controlled trials using calcium channel blockers in patients with nutcracker esophagus have been reported $(42,43)$. In the trial with nifedipine, there was a trend towards improvement in the early treatment phase that was lost as treatment continued. In the other trial, which used diltiazem, a statistically significant improvement over placebo was reported, but the study had significant methodological flaws. It thus appears that calcium channel blockers and nitrates are of limited value in NCCP patients. These agents may be worth trying in a small subgroup of patients with severe esophageal spasm.

Drugs that affect visceral sensation: Tricyclic antidepressants are used in a number of somatic and visceral pain disorders. The mechanism(s) whereby these agents suppress pain transmission is not well understood, but they appear to work 
both centrally and peripherally. It therefore appears rational to use tricyclics in NCCP because of the evidence that many NCCP patients have esophageal hyperalgesia. Two randomized, controlled trials have demonstrated efficacy of these drugs in patients with NCCP $(44,45)$. Patients in these studies were not selected based on demonstration of abnormal visceral perception; whether improved outcomes will occur if patients were selected on this basis remains to be determined.

\section{RECOMMENDATIONS}

Recommendations are also presented in Figure 1.

1. The gastrointestinal specialist must first ensure that cardiac disease has been adequately excluded and should consider other nonesophageal disorders such as chest wall pain, biliary colic, peptic ulcer disease, etc.

2. Endoscopic examination is a reasonable initial diagnostic test to exclude mucosal disease of the esophagus, stomach and duodenum. This is most useful when there are associated esophageal symptoms, especially dysphagia.

3. If available, $24 \mathrm{~h} \mathrm{pH}$ monitoring should be considered in patients without evidence of endoscopic esophagitis (or in whom endoscopy has not been performed) who have frequent (ie, daily) pain episodes.
4. An empirical trial of therapy with a PPI for approximately four weeks is a reasonable alternative to endoscopy and $24 \mathrm{~h} \mathrm{pH}$ monitoring, or following a negative endoscopy.

5. Esophageal manometry with provocative testing should be reserved for patients with nonreflux-related pain episodes that are significantly interfering with daily life and associated with patient anxiety because of diagnostic uncertainty.

6. Treatment:

a) Reassurance and education are the cornerstone of successful management.

b) If gastroesophageal reflux is suspected or documented as a cause of the atypical pain, a PPI should be used initially with subsequent step-down to lesser forms of antireflux therapy.

c) Calcium channel blockers or nitrates may be indicated in a small subgroup of patients with a markedly spastic, hypercontractile esophagus.

d) Tricyclic antidepressant (eg, amitriptyline in doses of 25 to $100 \mathrm{mg} /$ day) should be used in patients with nonspecific abnormalities on diagnostic tests but a suspected esophageal source. These drugs are particularly indicated in patients with documented visceral hyperalgesia.

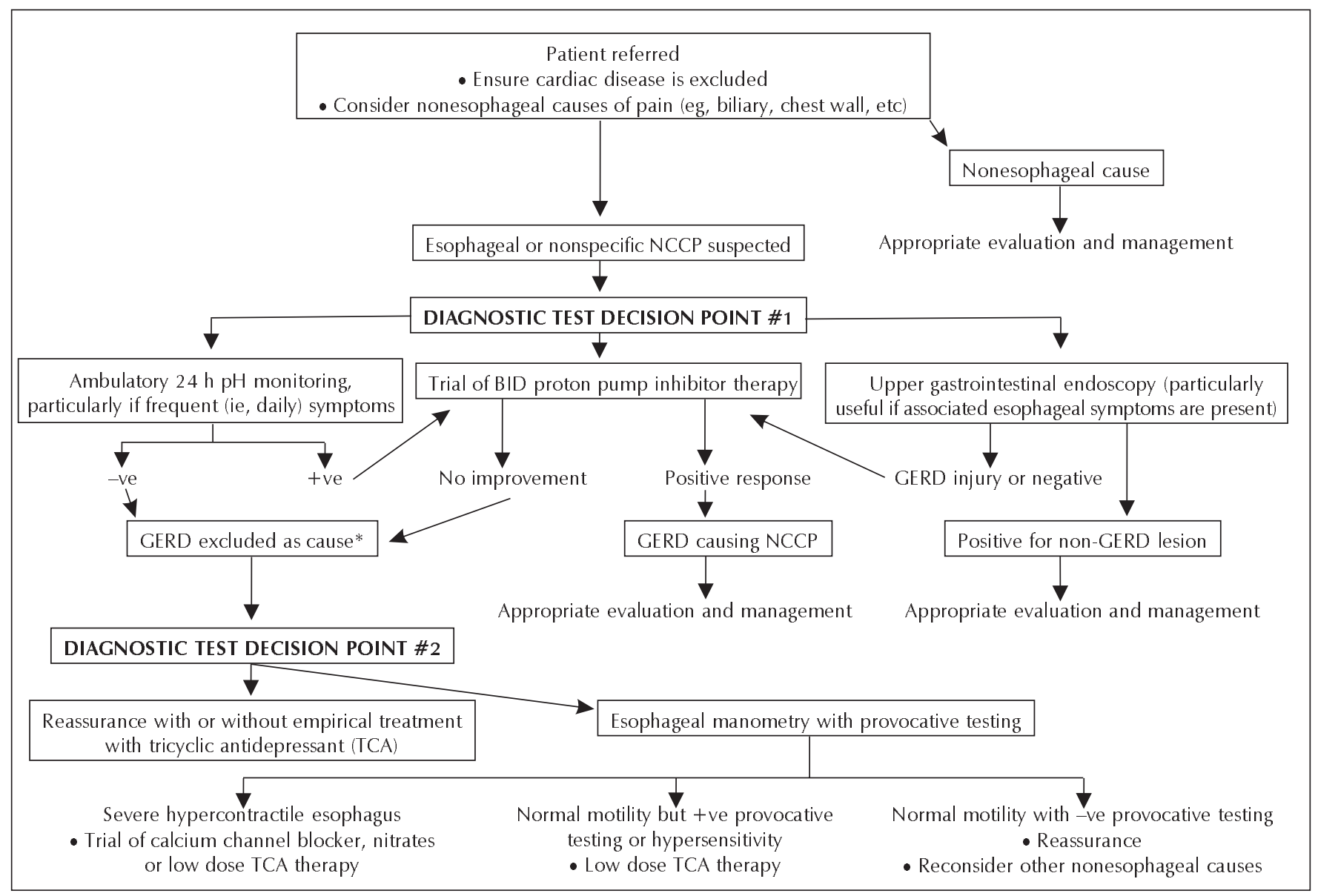

Figure 1) Suggested algorithm for the management of noncardiac chest pain (NCCP). *Rarely, patients may fail to respond to twice-daily proton pump inhibitor therapy despite gastroesophageal reflux disease (GERD) being the cause of the NCCP. In selected cases, $24 \mathrm{~h} p H$ monitoring done with the patient on treatment will help establish the cause of this. -ve Negative; +ve Positive 


\section{Canadian Association of Gastroenterology Practice Guideline Disclaimer}

This clinical practice guideline has been developed by the author on behalf of the Canadian Association of Gastroenterology (CAG) in order to outline the clinical approach to management problems or training issues. After preparation by the author, based on a review of the literature, each guideline is extensively reviewed by the CAG Practice Affairs Committee, composed of practitioners from across Canada. Changes are made, and once the guideline is felt to be appropriate, it is then circulated for further review by recognized Canadian experts and then amended further. Finally, the guideline is presented to the CAG Governing Board for further review and final approval.

Practice guidelines are intended to give an understanding of a clinical problem and outline one or more preferred approaches to investigation and management of the problem. While practice guidelines are intended to be useful to all physicians, it is recognized that specialists may rely less on practice guidelines than those in more general practice. These guidelines are intended to give a practical approach to a problem based on the current literature, but are not intended to be state-of-the-art reviews with extensive references.

Practice guidelines are developed to be of assistance to practising clinicians and are not intended to be the only approach to the management of clinical problems, nor are they intended to be considered as a 'standard of care'. The CAG Practice Affairs Committee recognizes that clinical circumstances may at times justify an approach different from that outlined in a practice guideline. It is also recognized that new developments in medical research and clinical practice may require subsequent changes to the practice guideline.

\section{REFERENCES}

1. Lee MG, Sullivan SN, Watson WC, Melendez LJ. Chest painesophageal, cardiac or both? Am J Gastroenterol 1985;80:320-4.

2. Ockene IS, Shay MJ, Albert JS, Weiner BH, Dalen JE. Unexplained chest pain in patients with normal coronary arteriograms. A follow-up study of functional status. N Engl J Med 1980;303:1249.52.

3. Richter JE. Gastroesophageal reflux disease as a cause of chest pain. Med Clin North Am 1991;75:1065-81.

4. Chauhan A. Syndrome X-Angina and normal coronary angiography. Postgrad Med J 1995;71:341-5.

5. Clerc N. Afferent innervation of the lower esophageal sphincter of the cat. An HRP study. J Auton Nerv Syst 1983;9:623-36.

6. Paterson WG, Abdollah H, Beck IT, Da Costa LR. Ambulatory esophageal manometry, pH-metry, and Holter ECG monitoring in patients with atvpical chest pain. Dig Dis Sci 1993;38:795-802.

7. Janssens J, Vantrappen G, Ghillebert G. Twenty-four hour recording of esophageal pressure and $\mathrm{pH}$ in patients with noncardiac chest pain. Gastroenterology 1986,90:1978-84.

8. Hewson EG, Dalton CB, Richter JE. Comparison of esophageal manometry, provocative testing, and ambulatory monitoring in patients with unexplained chest pain. Dig Dis Sci 1990;35:302-9.

9. Breumelhof R, Nadorp JHSM, Akkermans LMA, Smout AJPM. Analysis of 24-hour esophageal pressure and $\mathrm{pH}$ data in unselected patients with noncardiac chest pain. Gastroenterology $1990 ; 99: 1257-64$.

10. Marshall REK, Anggiansah A, Owen WA, Owen WJ. The relationship between acid and bile reflux and symptoms in gastro-oesophageal reflux disease. Gut 1997;40:182-7.

11. Mellow MH, Simpson AG, Watt L, Scmoolmeester L, Haye OL. Esophageal acid perfusion in coronary artery disease. Gastroenterology 1983:85:306-12.

12. Clouse RE, Staiano A, Landau DW, Schlacter JL. Manometric findings during spontaneous chest pain in patients with presumed esophageal "spasms". Gastroenterology 1983;85:395-402.

13. Balaban DH, Yamamoto Y, Liu J, DeSilvey D, Nuttal RK. Sustained esophageal contraction during noncardiac chest pain and symptomatic acid reflux: Characterization by 24-hour intraluminal ultrasonography. Gastroenterology 1997;112:A694.

14. Paterson WG, Wang H, Vanner SJ. Increasing pain sensation due to repeated esophageal balloon distention in patients with chest pain of undetermined etiology. Dig Dis Sci 1995;40:1325-31.

15. Richter JE, Barish CF, Castell DO. Abnormal sensory perception in patients with esophageal chest pain. Gastroenterology $1986 \div 91: 845-52$.

16. Davies HA, Jones DB, Rhodes J, Newcombe RG. Angina-like esophageal pain: Differentiation from cardiac pain by history. J Clin Gastroenterol 1985;7:477-81.

17. Voskuil JH, Cramer MJ, Breumelhof R, Timmer R, Smout AJPM. Prevalence of esophageal disorders in patients with chest pain newly referred to the cardiologist. Chest 1996;109:1210-4.

18. Clouse RE, Sfenson WF, Avioli LV. Esophageal motility disorders and chest pain. Arch Intern Med 1985;145:903-6.

19. Clouse RE, Lustman PJ. Psychiatric illness and contraction abnormalities of the esophagus. N Engl J Med 1983;309:1337-42.

20. Thompson JK, Koehler RE, Richter JE. Detection of gastroesophageal reflux: value of barium studies compared with a 24-hr $\mathrm{pH}$ monitoring. AJR Am J Roentgenol 1994;162:621-6.

21. Kahrilas PJ, Quigley EMM. Clinical esophageal pH recording: A technical review for practice guideline development. Gastroenterology 1996;110:1982-96.

22. Kahrilas PJ, Clouse RE, Hogan W. American Gastroenterological Association technical review on the clinical use of esophageal manometry. Gastroenterology 1994;107:1865-84.

23. Paterson WG, Marciano-D'Amore D, Beck IT, Da Costa LR. Esophageal manometry with provocative testing in patients with noncardiac angina-like chest pain. Can J Gastroenterol $1991 ; 5: 51.7$.

24. Katz PO, Dalton CB, Richter JE, Wu WC, Castell DO. Esophageal testing of patients with noncardiac chest pain or dysphagia. Ann Intern Med 1987;106:593-7.

25. De Caestecker JS, Pryde A, Heading RC. Comparison of intravenous edrophonium and oesophageal acid perfusion during oesophageal manometry in patients with non-cardiac chest pain. Gut $1988 ; 29: 1029-34$.

26. Bernstein LM, Baker LA. A clinical test for esophagitis. Gastroenterology 1958;34:760-81.

27. Deschner WK, Maher KA, Cattau EL Jr, Benjamin SB. Prospective evaluation of high-dose Bethanechol in investigation of esophageal chest pain. Dig Dis Sci 1989;34:1656-61.

28. Barish CF, Castell DO, Richter JE. Graded esophageal balloon distention. A new provocative test for noncardiac chest pain. Dig Dis Sci 1986;31:1291-8.

29. Deschner WK, Maher KA, Cattau EL Jr, Benjamin SB. Intraesophageal balloon distention versus drug provocation in the evaluation of noncardiac chest pain. Am J Gastroenterol $1990 ; 85: 938-43$

30. Rose S, Achkar E, Easley KA. Follow-up of patients with noncardiac chest pain: Value of esophageal testing. Dig Dis Sci $1994 ; 39: 2063-8$.

31. Ward BW, Wu WC, Richter JE, Hackshaw BT, Castell DO. Long-term follow-up of symptomatic status of patients with noncardiac chest pain: Is diagnos is of esophageal etiology helpful? Am J Gastroenterol 1987;82:215-8.

32. Hewson EG, Sinclair JW, Dalton CB. Twenty-four-hour esophageal 
Ph monitoring: The most useful test for evaluating noncardiac chest pain. Am J Med 1991;90:576-83.

33. Singh S, Richter JE, Hewson EG, Sinclair JW, Hacksaw BT. The contribution of gastroesophageal reflux to chest pain in patients with coronary artery disease. Ann Intern Med 1992;117:824-30.

34. Smout AJPM, Lam HDTh, Breumelhof R. Ambulatory esophageal monitoring. in noncardiac chest pain. Am J Med 1992:92(Suppl 5A):74S-80S.

35. Hewson EG, Sinclair JW, Dalton CB. Evaluation of 100 non-cardiac chest pain patients finds 24 hour $\mathrm{pH}$ study to be most useful diagnostic test. Gastroenterology 1989;98:58 A.

36. Marciano-D'Amore DA, Paterson WG, Da Costa LR, Beck IT. Omeprazole in $\mathrm{H} 2$ receptor antagonist-resistant reflux esophagitis. J Clin Gastroenterol 1990;12:616-20.

37. Fass R, Fennerty MB, Yalam JM, Camargo L, Garewal H, Sampliner RE. Evaluation of the "omeprazole test" in patients with noncardiac chest pain. Gastroenterology 1997;112:A114.

38. DeMeester TR, O'Sullivan GC, Bemudes O, Midell AL, Cimochowski OE, O'Drobinak J. Esophageal function in patients with angina-type chest pain and normal coronary angiogram. Ann Surg $1982: 196: 488-9$.

39. Achem SR, Kolts BE, Wears R, Burton L, Richter JE. Chest pain associated with nutcracker esophagus: a preliminary study of the role of gastroesophageal reflux. Am J Gastroenterol $1993 ; 88: 187.92$

40. Stahl WA, Beton RR, Johnson CS, Brown CL, Waring JP. High-dose ranitidine in the treatment of patients with non-cardiac chest pain and evidence of gastroesophageal reflux. Gastroenterology 1992;102:A168.

41. Achem SR, Kolts BE, MacMath T, et al. Effects of omeprazole versus placebo in treatment of noncardiac chest pain and gastroesophageal reflux. Dig Dis Sci 1997;42:2138-45.

42. Richter JE, Dalton CB, Bradley LA, Castell DO. Oral nifedipine in the treatment of noncardiac chest pain in patients with the Nutcracker Esophagus. Gastroenterology 1987;93:21-8.

43. Cattau EL, Castell DO, Johnson DA, Spurling TJ, Hirszel R. Diltiazem therapy for symptoms associated with nutcracker esophagus. Am J Gastroenterol 1991;86:272-6.

44. Clouse RE, Lustman PJ, Eckert TC, Ferney DM, Griffith LS. Low dose trazodone for symptomatic patients with esophageal contraction abnormalities. Gastroenterology 1987;92:1027-36.

45. Cannon RO III, Quyyumi AA, Mincemoyer R, et al. Imipramine in patients with chest pain despite normal coronary angiograms. N Engl J Med 1994;330:1411-7. 


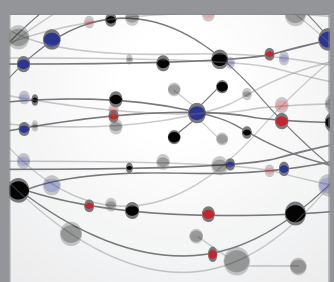

The Scientific World Journal
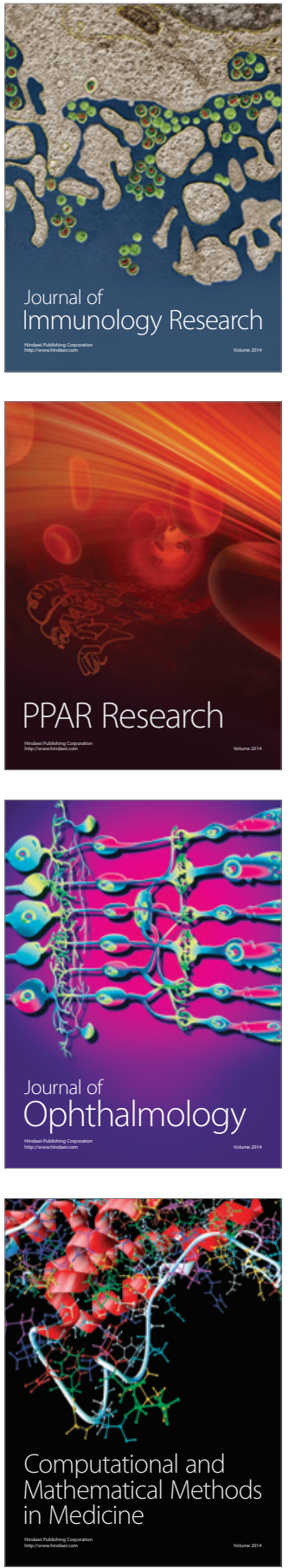

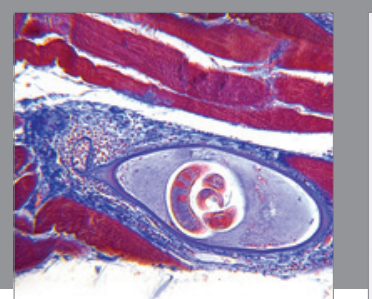

Gastroenterology Research and Practice

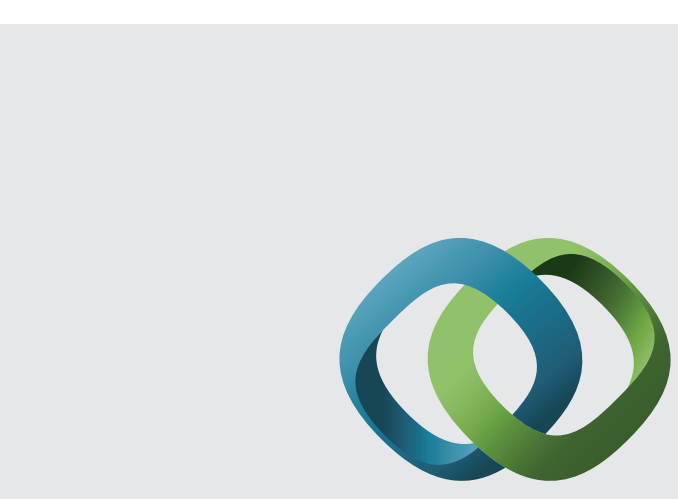

\section{Hindawi}

Submit your manuscripts at

http://www.hindawi.com
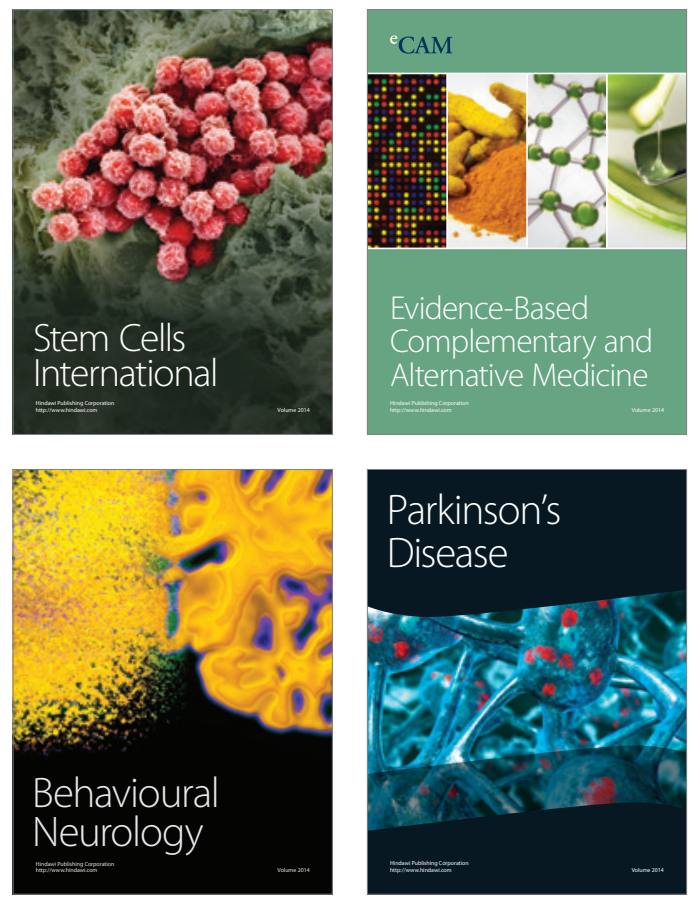
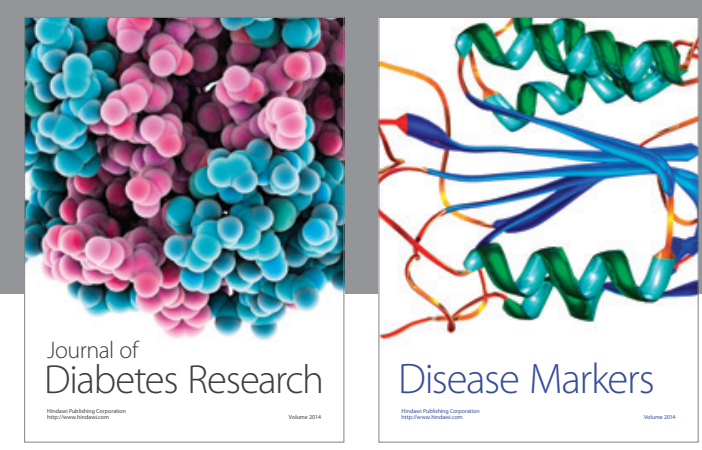

Disease Markers
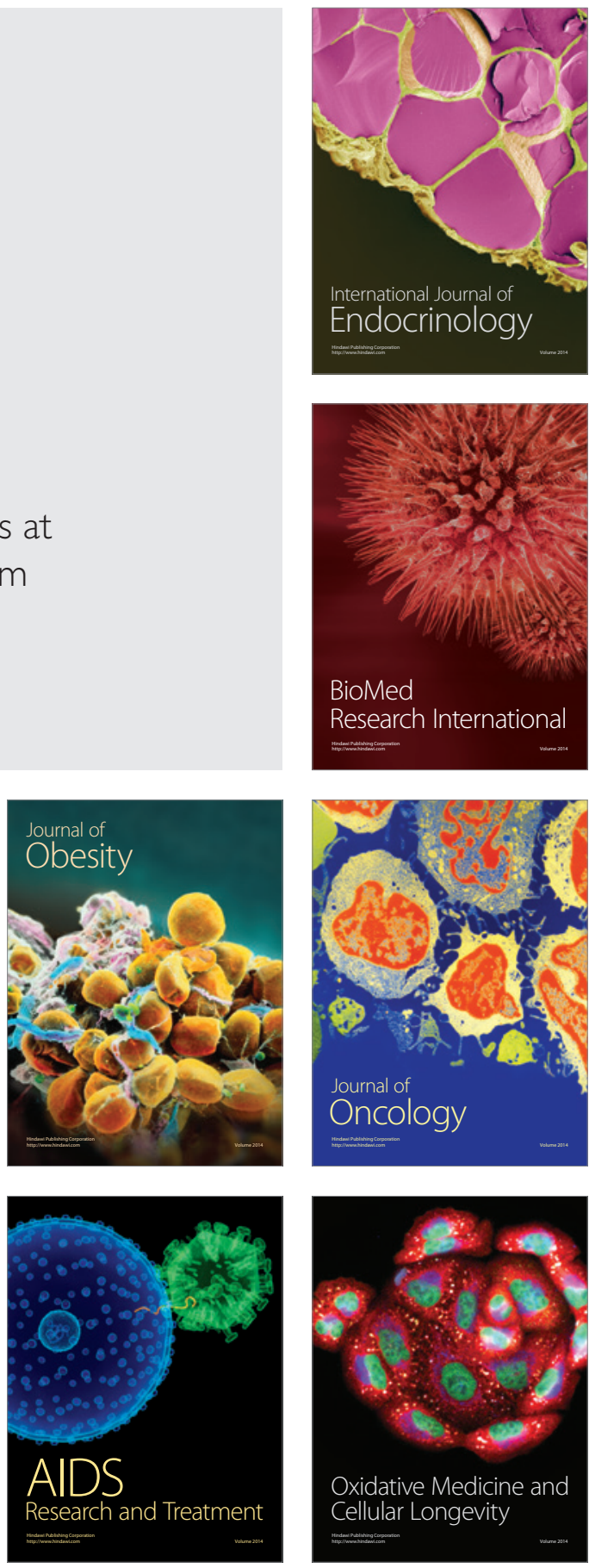